\title{
El país de las Maravillas. Respuesta a la respuesta de S. Gutiérrez
}

\author{
Miquel Barceló *
}

Quisiera -y es la expresión de un deseo que sé de sobras que será insatisfecho- dejar bien claro que nada personal he tenido ni tengo con S. Gutiérrez. Ella misma, si quiere, puede dar testimonio de que mis relaciones con ella a lo largo de estos últimos años, coincidencias en coloquios y congresos, fueron siempre cordiales. La única razón, pues, de mi crítica (1996) a recientes trabajos de S. Gutiérrez (1995a, 1996a) es de orden intelectual y, por extensión, académico. De hecho, hice ya públicas algunas de mis discrepancias en los debates del Coloquio sobre la cerámica alto-medieval en el sur de al-Andalus (ed. A. MALPICA, 1993), celebrado del 16 al 18 de octubre de 1990, como I Encuentro de Arqueología y Patrimonio, en Salobreña (Granada).

Justamente fueron estas discrepancias las que me indujeron a releer el texto de la tesina de S. Gutiérrez publicado en 1988 con el título de Cerámica común paleoandalusí del sur de Alicante (siglos VII-X). Desde esta relectura seguí con atención sus diferentes publicaciones que, en realidad, vinieron a ser variaciones sobre la propuesta ceramológica del libro de 1988. Fue despues de la lectura de su texto en Arbor (1995a) y de su comunicación después retirada de las Actas del Coloquio de Almería (GUTIÉRREZ, 1996a), cuando decidí exponer públicamente de forma escrita mis objeciones, en espera, como ya advertí, de la recensión que la inminente publicación de su libro (Tudmir: de la antigüedad tardía al mundo islámico) va a merecer. Era, por tanto, una crítica provisional.
En su respuesta S. Gutiérrez (GUTIÉRREZ, 19966) elude, creo, los puntos principales de mi crítica. Lamenta, sin embargo, unas "maneras desabridas que no considero propias del discurso científico" (p.37). Se trata, evidentemente, de una opinión sobre el tono de mi escrito. Para mí, este tono es simplemente diligente y severo, al estilo de las muchas controversias que pueden leerse en revistas especializadas europeas. Reconozco que este tono puede resultar insólito en el ambiente académico español. Este carácter de insólito no es nada ajeno al marasmo intelectual en el que transcurren los intentos de una viscosa investigación española, donde las palabras pueden cambiar de sentido e incluso llegar a no tener ninguno con la entusiasta complicidad de los usuarios: "discurso científico", "hipótesis", "lugares estratégicos", "transición", "transición en sentido pleno", "continuidad", "ruptura", "transculturación", "aculturación", "poblamiento", "territorio", etcétera. El lector podría reconocer en los primeros párrafos de la respuesta de S. Gutiérrez unas maneras de mansetud dirigidas a captar la benevolencia del lector con invocaciones jeremíacas a que, por ejemplo, "se analicen mis hipótesis de acuerdo con su desarrollo científico..." -frase ejemplar de como no decir nada con impostación- citando nombres de ilustres profesores del Area de Arqueología como R. Olmos o J. Arce. El lector podría hacerlo, pero sería sólo su opinión y quizá no la intención de S. Gutiérrez.

En mi opinión, despues de conocer la lamentable secuencia de acciones que pusieron en

* Universidad Autónoma de Barcelona 
movimiento mi intervención en el coloquio de Almería y el escrito subsiguiente, mi crítica era necesaria, más necesaria de lo que en un principio creí. En primer lugar, algunos, con diferente intensidad, teníamos la impresión de que la investigación arqueológica, en el sentido más amplio, sobre al-Andalus -empezada con una euforia que desde la perspectiva actual era desmesurada- había alcanzado un estadio que reclamaba severidad crítica.

El libro de P. Guichard de 1976 había fundamentado la existencia de una migración bereber en la parte oriental de al-Andalus. Las reacciones, en su mayoría turbias, que suscitó esta investigación, fueron fugaces y triviales. La aceptación, reducida a ciertos círculos de investigación, del conjunto de pruebas articulado por P. Guichard sobre este proceso migratorio no condujo, por otra parte, a la proyección de estudios dedicados a detallar y hacer más compleja la secuencia migratoria y su posible relieve espacial. A pesar de ser benevolentemente citado, el texto de P. Guichard iba convirtiéndose, cada vez más, en una mera referencia de significado incierto. Se insinuaba con creciente intensidad que, de pronto, alguien, en algún sitio de la "academia" española, declararía el texto como obsoleto. Se imponía, de nuevo, la vieja ley que parece regir la investigación del "medievalismo" español: no existen conocimientos adquiridos, matrices conceptuales activas que puedan producir conocimientos de los que sea imposible retroceder. Así, casi sin sentir, el texto de P. Guichard, angular en la comprensión de al-Andalus, iba siendo desconsiderado. Y a partir de una propuesta ceramológica de una extrema simplicidad, como pienso mostrar en un trabajo próximo, se esbozaba un esquema de la formación de la sociedad de šarq al-Andalus que relegaba su elemento más activo, la inmigración bereber, a un componente incapaz de hacer inteligible el indudable nuevo orden campesino. Esta operación iba haciéndose con sigilo, a tientas a veces, y con desigual grado de conciencia. En suma, se volvía hacia la "historia de España". El gran esfuerzo de P. Guichard se había convertido, finalmente, en "acertadas opiniones" según palabras de S. Gutiérrez (1995c, p. 166).
La participación, cada vez más frecuente e intensa, de arqueólogos en proyectos para el conocimiento de al-Andalus fue objeto de una particular bienvenida. Pasado el tiempo ha quedado claro que su procedencia, bien de la arqueología prehistórica o de la "clásica", ponía impedimentos conceptuales serios -ciertamente no insalvables- a la elaboración de una arqueología de al-Andalus. Una arqueología necesitada de una especificidad de método y comprensión que no podía improvisarse. La excavación, sin duda, era y sigue siendo un ejercicio indispensable para producir ciertos conocimientos pero es insuficiente. Tampoco ninguna tipología cerámica, o de cualquier serie objetual, puede explicar nada, ni siquiera puede explicarse a sí misma.

El trabajo de S. Gutiérrez desde 1988 empezaba a dar un relieve cada vez más perceptible a esta confusa operación. Las reacciones que ha suscitado mi crítica a S. Gutiérrez confirman, a mi juicio, que sus escritos, incluso en su misma tosquedad conceptual, revelan una corriente de opinión más dilatada de lo que estos mismos escritos dejaban entrever. Mi crítica, inesperadamente para mí, puso de manifiesto el posible alcance de esta opinión, poco visible en los textos pero oralmente muy reiterada. La respuesta de S. Gutiérrez a mi crítica es sólo la parte más perceptible de ella y quizá la menos relevante.

Yo creí que había argumentado bien que S. Gutiérrez lee mal. Nunca, sin embargo, pretendí precisar si este mal leer era deliberado o no. Sigo teniendo la convicción de que lee mal. $Y$ a tenor de las reacciones que parece que mi crítica ha provocado, parte de la gente de la profesión lee también mal o, al menos, lee mal mi crítica a S. Gutiérrez. No me cuesta reconocer que esta crítica ha supuesto pérdida de amigos, colegas que rehuyen mi presencia, reticencias, palabritas y alguna carta en la que se me acusa de excomunicador y otras lindezas. Sé, además, que $\mathrm{S}$. Gutiérrez dice haber recibido cartas de solidaridad y adhesión de ilustres catedráticos nacionales y extranjeros. Bien. Debo decir que asumo, como suelen decir los remirados, los costes que mi crítica puede conllevar. 
No voy a comentar con detalle -en espera de las oportunas recensiones a su libro de próxima publicación- su respuesta, que es una yuxtaposición de lugares comunes más o menos trivialmente expresados. S. Gutiérrez en ningún momento responde a nada. Me limitaré a señalar dos ejemplos de que sigue leyendo mal y mostraré gráficamente cuál es su propuesta, atendiendo a lo publicado hasta ahora.

S. Gutiérrez (1996b, p.44) sigue sin entender que la "rigidez" y la "estabilidad" de los espacios hidráulicos no son lo mismo que "inmutabilidad" y "perdurabilidad" y que los posibles procesos de aluvionamiento o modificaciones topográficas debidas a otras causas nada tienen que ver con los principios a partir de los cuales se diseña y se construye un espacio hidráulico. En todo caso, si en algo afectan estos posibles procesos de aluvionamiento o erosión, es al método de estudio que debe adaptarse a las circunstancias especííicas de cada caso, pero no afecta en nada a los principios de la hidráulica tradicional. Dicho de otra manera, los procesos de aluvionamiento o erosión o el efecto arrasante de una excavadora alteran, entierran o destruyen el espacio irrigado, pero no los principios según los cuales fue concebido y creado. Además, hay que hacer notar que incluso en los casos donde se han producido aluvionamientos o colmataciones, a menudo, la existencia de un diseño de un espacio agrario ha dejado su impronta en el parcelario actual que puede ser detectado y estudiado mediante las técnicas de la fotointerpretación. Los márgenes del marjal y el marjal mismo del Bajo Segura siguen, pues, sin estudiar.

En efecto, H. Kirchner y C. Navarro (1993, p. 160) se refieren a "...inmutabilidad de los límites de rigidez que, incluso detrás de una radical transformación de un espacio irrigado, siempre pueden ser reconocibles". Está claro que la inmutabilidad no se refiere al espacio hidráulico sino a los límites de rigidez, es decir, a la también llamada acequia madre que condiciona toda la circulación posterior del agua. ¿O no? S. Gutiérrez leyó otra vez mal.

En la p. 39, S. Gutiérrez (1996b) insiste en sugerir que el matrimonio de la hija de Teodomi- ro con un Banū Jațțāb es un indicador adecuado de una tendencia más amplia de nupcialidad de ŷundíes egipcios con mujeres indígenas, a través de la cual se produciría la difusión técnica de la noria y sus arcaduces. Justamente, el análisis de la absorción por parte de los linajes agnaticios árabes de los "orígenes" indígenas maternos no permite la inferencia de esta tendencia nupcial; ni esta tendencia nupcial es una forma adecuada de explicar cualquier difusión técnica. La selección técnica es un fenómeno complejo que no admite una semejante explicación: varón egipcio se casa con hembra indígena e introduce la noria con su arcaduz. En el reciente libro Technological choices, de P. Lemonnier (1993), no aparece jamás contemplado el supuesto de la vía nupcial a la difusión y selección técnica. El análisis, insisto, de P. Guichard no puede ser aducido para sustentar semejante cosa. S. Gutiérrez ha vuelto a leer mal.

Lo peor de todo es que en todos los escritos publicados hasta ahora por S. Gutiérrez se hace, con diversos grados de claridad, la propuesta siguiente para explicar la formación de la sociedad andalusí en el área administrativa de Tudmir:

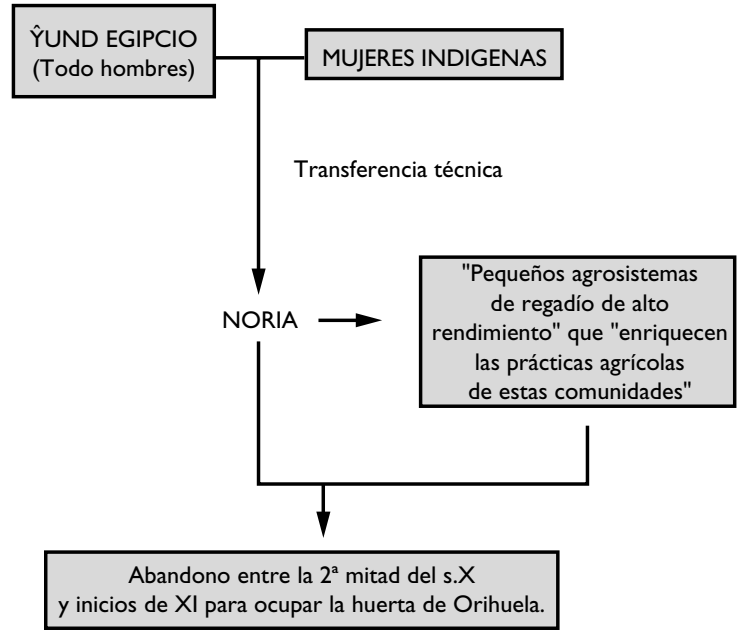

Parece ser que los ŷundíes egipcios o sirios pueden hacer diferentes funciones según convenga: en Tudmir se casan con mujeres indígenas e introducen norias con arcaduces $y$, en cambio, según E. Manzano (1993), los ŷundíes sirios son cualquier cosa menos campesinos; son vigi- 
lantes recaudadores de las asignaciones fiscales sobre indlggenas -mujeres y hombres- cedidas por el estado. Parece, además, que no necesitaron para nada mujeres indígenas y, por lo que sabe, o por lo menos E. Manzano no lo menciona, no introdujeron las norias con sus arcaduces. Este supuesto explicativo es el que propone S. Gutiérrez y su único fundamento son los arcaduces -parecidos a un tipo de arcaduz egipcio actual que publica Schioler-. Y el fundamento de la existencia de la población femenina indígena -de los varones no se habla nunca- son dos registros cerámicos de, parece, difícil conciliación: los útiles de cocción y almacenaje por un lado, y los de servicio por el otro; los primeros indígenas, los segundos islámicos. La diversa función crea así la etnia de los productores.

Este es el trazo informe, y no otro, que se ofrece como explicación de una supuesta especificidad en la formación de la sociedad andalusí de Tudmir. La corriente de opinión que S. Gutiérrez puede representar debe de asumir este garabato, llamémosle conceptual, con la misma serenidad y decisión con que yo he asumido su furtiva hostilidad.

En el fondo, creo, se está discutiendo otra cosa: el contenido que debe tener la arqueología medieval en general y la de al-Andalus en especial, y el papel y función que en esta construcción de la arqueología histórica deben tener los arqueólogos de excavación y la relevancia que debe atribuirse a la excavación misma. Y ello, aparte del rebrote atractivo que la misma noción de "Historia de España" genera para expulsar o hacer invisibles las sociedades diferentes. Estamos, pues, como siempre. Parece, en palabras de mi amado poeta, que no fue ayer.

Quiero señalar, por último, un buen ejemplo de cómo no insultar y otro ejemplo de cómo seguir leyendo mal.

En la p. 38, S. Gutiérrez (1996b) -pidiendo, eso sí, permiso al lector para hacer un "paralelo jocoso"- compara mis, según ella, "conceptuaciones" (sic), "globalmente asumidas por la comunidad científica", con las de Newton, con lo cual se ahorra citarlas. No se trata, en mi opinión, de nada jocoso. Si se quiere convertir a alguien de baja estatura en un enano, se le pone un gigante al lado, se sonríe, y basta. A continuación, S. Gutiérrez equipara el concepto de "incastellamento" formulado por P. Toubert con los "conceptos" (?) de "ataifor", "redoma", supuestamente acuñados -ilos "conceptos", los objetos o las palabras?- por G. Rosselló. La confusión es, pues, total.

No creo justo que una discusión suficientemente importante como para poder convertirse en un debate serio quede reducida a los términos en que buenamente la plantea $\mathrm{S}$. Gutiérrez. Mi deseo es que salga a la superficie la corriente de opinión que S. Gutiérrez se esfuerza por representar. Nada hay, pues, de personal. Que se debata. Las palabras estan hechas para entendernos pero también para entenderlas. Nunca he querido vivir en el país de las maravillas.

\section{BIBLIOGRAFÍA}

BARCELÓ, M. (1996): " Acerca de nada. Consideraciones sobre dos artículos de S. Gutiérrez", Arqueología y Territorio Medieval, 3, pp. 21-36.

GUICHARD, P. (1976): Al-Andalus. Estructura antropológica de una sociedad islámica en Occidente, Barcelona (=1995, Granada).

GUTIÉRREZ, S., (1988): Cerámica común paleoandalusí del sur de Alicante (VII-X), Alicante.

GUTIÉRREZ, S., (1995a): "El origen de la huerta de Orihuela entre los siglos VII y Xl: una propuesta arqueológica sobre la explotación de las zonas húmedas del Bajo Segura", Arbor, CLI, pp. 65-94.

GUTIÉRREZ, S., (1995c): "La experiencia arqueológica enel debate sobre las transformaciones del poblamiento altomedieval enel SE. de al-Andalus: el caso de Alicante, Murcia y Albacete", en BOLDRINI, E., FRANCOVICH, R., eds., Acculturazione e mutamenti, Firenze.

GUTIÉRREZ, S., (1996a): "El aprovechamiento agrícola de las zonas húmedas: la introducción del arcaduz en el sureste de al-Andalus (siglos VIII y IX)", Arqueología y Territorio Medieval, 3, pp. 7-19.

GUTIÉRREZ, S., (1996b): "Acerca del origen de la huerta de Orihuela y la explotación de las zonas húmedas del Bajo Segura entre los siglos VII y XI. Respuesta a M. Barceló", Arqueología y territorio medieval, 3, pp. 37-48. 
KIRCHNER, H. Y NAVARRO, C. (1994): "Objetivos, métodos y práctica de la Arqueología hidráulica", Arqueología y Territorio Medieval, I, pp. 159-182.

LEMONNIER, P, éd., (1993): Technological choices, Routledge, London \& New York.
MALPICA, A., ed., (1993): La cerámica altomedieval en el sur de al-Andalus, Granada.

MANZANO, E., (1993): "El asentamiento y la organiza-

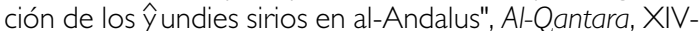
2, p. 327-359. 